\title{
THE MIXING AND MOVEMENT OF WATER IN THE ESTUARY OF THE THAMES
}

\author{
By W. S. Preddy \\ Water Pollution Research Laboratory, Watford
}

(Text-figs. I-9)

In Great Britain many estuaries are seriously polluted by discharge of untreated or partially treated sewage and industrial waste waters. In addition to the unpleasant effects produced in the estuary itself, fisheries in the upper reaches may be damaged, as a barrier of deoxygenated or poisoned water may be formed through which migratory fish, such as salmon, are unable to pass. In some estuaries conditions are so bad that at times the water is completely deoxygenated; reduction of sulphate may then occur, resulting in the evolution of hydrogen sulphide which may cause nuisance from smell, blacken paint-work, and increase corrosion of metals.

When an effluent is discharged into a freshwater stream flowing in one direction only, the concentration in the water, at a given distance from the point of discharge, of any soluble component which decays at a known rate, can be calculated with reasonable accuracy. It is also possible to predict, although with greater error, the effect of oxidizable substances in the effluent on the dissolved oxygen content of the river water, provided the rate of re-oxygenation from the air is known (Phelps, I947). It is much more difficult, however, to predict the effects of pollution in an estuary where the movement of water resulting from the inflow of fresh water and from tidal action is much more complicated. As estuaries are important economically the problem is being investigated in this country and in America (Ketchum, 1950, 1951).

In an estuary the inflow of fresh water tends to carry sea water seawards by displacement. On the other hand, sea water is carried towards the head of the estuary by the mixing brought about by tidal action. These two processes determine the salinity of the water in the estuary at any time, and the present paper suggests a method of calculating the degree of mixing in an estuary from observations of the flow of fresh water and the resultant salinities.

\section{Types of estuaries}

\section{Mixing IN Estuaries}

Stommel \& Farmer (I952) divide estuaries into four types according to the degree of vertical mixing: (I) Vertically mixed estuaries are so thoroughly mixed vertically that there is no measurable difference in the salinity from the surface 
to the bottom. (2) Slightly stratified estuaries are characterized by only slight vertical stratification; the vertical mixing is intense. (3) Highly stratified estuaries show big differences of salinity between the surface and bottom; often there is no fresh water in the lower layer. In (4) Salt-wedge estuaries, the sea water intrudes up-stream as a wedge.

In this paper only estuaries of type I or 2 will be considered-and only those in which the salinity is sufficiently constant, both vertically and across the stream, to permit the intermingling of salt and fresh water to be regarded as a one-dimensional problem without appreciable error. An extension of the theory would be required for other types of estuaries.

The Thames Estuary (which is now being investigated by the Water Pollution Research Laboratory) is of type 2; not only the salinity but also the concentration of dissolved oxygen and other dissolved substances is almost constant in a cross-section. Pillsbury (1939) considered the relations between erosion of the bed and the tidal flow in estuaries which have little vertical salinity stratification. He showed that the width of such an estuary should increase exponentially towards the sea, and that the distance of tidal flow should be constant. The Thames is a good example of an estuary of this type. The width and the area of cross-section increase exponentially except in a region near Tilbury where the estuary is narrow and deep. The average length of tidal flow is everywhere about 8 or 9 miles except near Teddington Weir, and the mixing during one tidal period must be confined in a length of this order. The theory developed in this paper probably applies to all estuaries of the Pillsbury type.

\section{Causes of mixing}

The entry of water into an estuary from land sources displaces the water of the estuary towards the sea, the magnitude of the displacement at any point depending on the area of cross-section. If the estuary water moved without any mixing between adjacent sections, each unit of water pushing the unit in front of it without overtaking in any way, only the displacement and the oscillation due to the tide would occur, and the sea water would be driven from the estuary. As a result, however, of movement caused by both tidal and land-water flow, much mixing in fact takes place between the waters at different distances along the estuary. It may be expected that the dispersal of the water by mixing depends on many factors. One of these factors is the difference in the pattern of flow between the flood and ebb tides. If the area of cross-section is large, water which travels farthest up the estuary in the fastest currents may not mix completely at slack water, and the amount which is returned to the original neighbourhood will depend on the difference in position of the fastest currents of the ebb and flood tides. Turbulence, wind, waves, shipping, obstacles, and the nature of the bed will also influence the amount of mixing. At one place on the side of the Thames Estuary the flow of 
water is said to be always in one direction because of the formation of a very large eddy on the ebb tide; such eddies must also influence the amount of mixing. It is also to be expected that there will be a difference in the amount of dispersion of the water for spring and neap tides. In this paper the influence of the different tides will not be considered, but only the average amount of mixing during a long period will be calculated.

The movement of the water may be regarded as composed of three parts: displacement due to the flow from the land, tidal oscillation, and dispersal by mixing. Consider a unit of water which is contained between two crosssections of the estuary which are very close to each other. Let the point, $B$, be midway between the cross-sections. At the corresponding time of the next tidal cycle this water will have been dispersed over the maximum distance of flow, to give a distribution curve similar to that shown in Fig. I $a$, in which $R$, the amount of the unit of water per unit of length, is plotted against distance along the estuary. The curve represents a dispersal which is additional to the displacement due to the entry of water from the land. $R$ must be zero beyond the limits of the length of flow of the fastest currents during the tidal cycle, and is likely to be small beyond the mean distance of flow. Such a distribution curve exists for every point along the estuary. The water which has been dispersed during one tidal cycle will, during the next tide, be further dispersed according to the dispersion curves appropriate to the positions reached after the first tide. The result will be the dispersion curve corresponding to an interval of two tidal cycles; the sets of curves corresponding to different intervals of time can be calculated from each other.

The second moment of the curve is $\int_{-\infty}^{\infty} R x^{2} \mathrm{~d} x$, where $x$ is the distance from the original position. It is well known that if a dispersal according to a distribution curve of second moment $M_{1}$ is followed by another dispersal of second moment $M_{2}$, the resulting distribution has a second moment $M_{1}+M_{2}$. A set of dispersion curves exists for an estuary, and represents the mixing which causes sea water to move into the estuary against the general direction of flow. But if the water were repeatedly mixed in a way represented by a second set of dispersion curves, which differed in detail but had the same second moments, the movement would be almost identical. Hence it is not possible to calculate the exact shape of the curves from a consideration of the salinity balance during a long period. However, a complicated dispersion can be represented by a simpler dispersion which is repeated a number of times. For example, a binomial distribution approaches a normal distribution as the index increases. Hence a simplified form of the dispersion curves, with only a small number of arbitrary constants, can be taken, and the constants calculated, so that repeated mixing according to the simplified form is almost the same as the actual mixing in the estuary. 


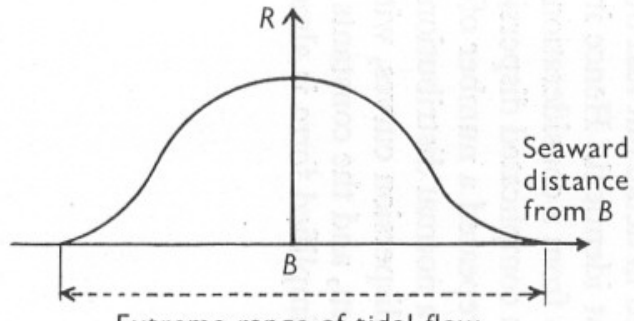

Extreme range of tidal flow

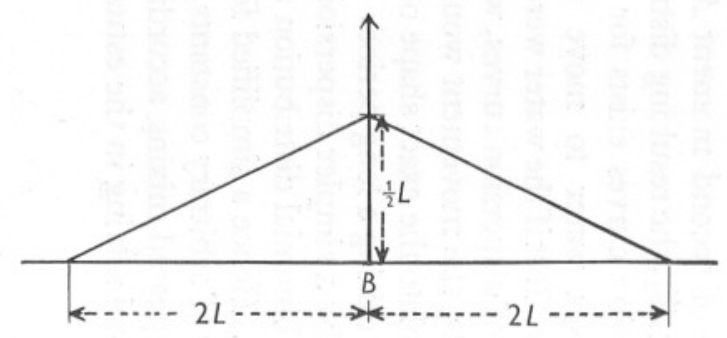

d
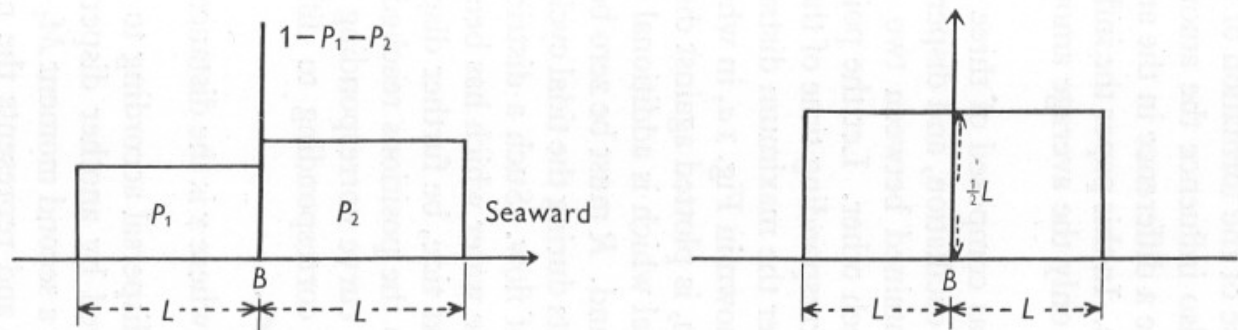

$b$

$c$

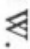

a

$\checkmark$

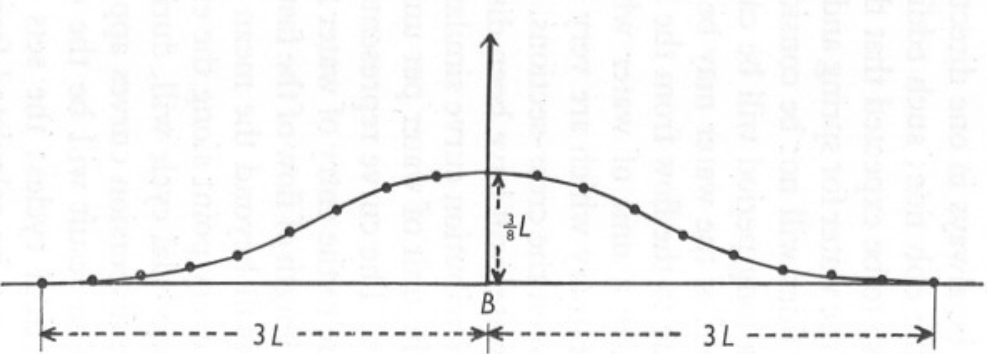

$e$

Fig. I. Diagrams illustrating distribution of a unit volume of water in an estuary. $a$, distribution caused by tidal mixing; $b$, assumed equivalent distribution. Successive dispersals when $P_{1}=P_{2}=\frac{1}{2} ; c$, after time $T ; d$, after time $2 T ; e$, after time $3 T$. 
Asymmetry of mixing

In an estuary of which the area of cross-section decreases in a direction away from the sea, finally dwindling into that of the river at the head, the dispersion curves, whether actual or the equivalent simplified form, cannot be symmetrical. The mixing causes some of the water from any particular section to move landwards into the adjacent, smaller, section, in which the salinity is lower. To make space for the more saline water, the water already in the upper section must move towards the sea by mixing. Hence it is necessary to take a form of the simplified dispersion curves which allows the centre of the water to move towards the sea. This need not be so in an inlet of constant area of cross-section, in which a unit of water might disperse symmetrically until it was unable to continue to do so because some of the water had reached the end of the inlet.

An example may make the equilibrium clear. Consider an estuary which can be divided into adjacent sections $\mathrm{I}, 2,3, \ldots, m$ of equal length, whose volumes are $v, 2 v, 4 v, \ldots, 2^{m-1} v$, respectively, the last section being next to the sea. The mixing can be considered as an exchange of water between the sections. If the amount exchanged is proportional to the volumes, and I unit is exchanged between the Ist and 2nd sections, then 2 units are exchanged between the 2nd and 3 rd sections, 4 units between the 3 rd and 4 th sections, and so on, the last section exchanging $2^{m-1}$ units with the sea. The volume of water in each section remains constant, but the centre of gravity of the water of each section moves seaward.

\section{Representation OF THE Mixing}

Since the detailed shape of the dispersal curves cannot be calculated from the salinity data, it is necessary to represent them in a simplified manner. It will be shown later that two conditions have to be satisfied at every point along the estuary, and hence each curve will have two arbitrary constants which can be determined from the measured salinities. As there are many families of curves which produce almost identical effects, if the water is dispersed many times, a method of representation which simplifies the mathematics may be selected. Consider a unit of water which is contained in a narrow cross-section of the estuary at $B$ (Fig. I $b$ ). After a lapse of time, $T$, the mixing may be represented as shown in the figure. $P_{1}$ is the proportion of the water which is distributed uniformly over a distance $L$ towards the sea, and $P_{2}$ the proportion of the water distributed uniformly over the distance $L$ in the opposite direction. The remainder of the water $\mathrm{I}-P_{1}-P_{2}$ is left in its original position.

$P_{1}$ and $P_{2}$ have mathematical existence only. It is assumed that values exist for $P_{1}, P_{2}$ and $L$ such that if the water is repeatedly mixed in accordance with these values, the dispersion of a unit of water is almost the same as the actual dispersion. 
It is desirable that the assumed equivalent mixing should resemble the actual mixing in the estuary as closely as possible, so that agreement between the two systems of mixing occurs quickly and long calculations are avoided. This is the reason why $P_{1}+P_{2}$ has not been equated to I. A proportion, I $-P_{1}-P_{2}$, of the water is unmixed. If there is little mixing $P_{1}+P_{2}$ is small and the proportion $\mathrm{I}-P_{1}-P_{2}$ is large, corresponding to the large amount of water which must remain very near its original position in the estuary. It has already been shown that if $T$ is equal to the tidal period, say $T_{0}$, then $L$ should be of the same order as the mean length of flow of the tide. If $n T=T_{0}$, then $L$ should be of the same order as the mean length of flow of the tide divided by $n^{\frac{1}{2}}$, by the theorem of addition of second moments. $P_{1}+P_{2}$ must not be greater than $I$. If the values of $L$ taken lead to calculated values of $P_{1}+P_{2}$ which are greater than unity in a section of the estuary, it follows that the mixing in this section is substantial over a greater distance than the assumed value of $L$. Hence $L$ should be increased in the section, and the values of $P_{1}$ and $P_{2}$ recalculated. If at some point there is little mixing, then the actual dispersion curve for this point will have high values at its centre and low values at its extremes. This corresponds to low values of $P_{1}$ and $P_{2}$, and the assumed equivalent mixing curve also has high values at its centre, since the proportion of the water, $\mathrm{I}-P_{1}-P_{2}$, which remains in its original position, is large. If the calculated values of $P_{1}$ and $P_{2}$ are exceedingly small, the actual mixing in the estuary can be substantial only in a shorter distance than $L$, and it is better to decrease $L$ and recalculate $P_{1}$ and $P_{2}$.

An example of repeated mixing in accordance with numerical values of $P_{1}$ and $P_{2}$ may clarify the assumption which has been made. The simplest case is that when $P_{1}=P_{2}=\frac{1}{2}$ for all points in the estuary. The water, which was initially at the point $B$ is, after an interval of time $T$, distributed as in Fig. I $c$. During the next interval of time $T$, this water is further scattered from the position it has already reached, and its distribution becomes that of Fig. I $d$. After a total lapse of time $3 T$ the water has reached a position as shown in Fig. $\mathrm{I} e$, and the shape of its distribution curve is approaching that of a normal error curve, as, of course, it must.

\section{Equations relating $P_{1}$ and $P_{2}$ to observable data}

The two following conditions must be satisfied. (i) During any period the net amount of salt carried upstream past any point is equal to the amount present above this point at the end of the period, minus the amount present at the beginning, minus any amount discharged into the estuary above the point during the period considered. (ii) The volume of water carried upstream past the point during the period must conform to a similar condition.

The volume of fresh water entering the estuary is completely accounted for by the displacement mentioned above, and hence the values of $P_{1}, P_{2}$ and 
$L$ must be such that the mixing process alone does not cause a net flow of water either upstream or downstream.

The salinity data available for the Thames Estuary made it convenient to consider conditions at half tide, which is defined as the time at which the height of the water is the mean of the heights at high and low tide.

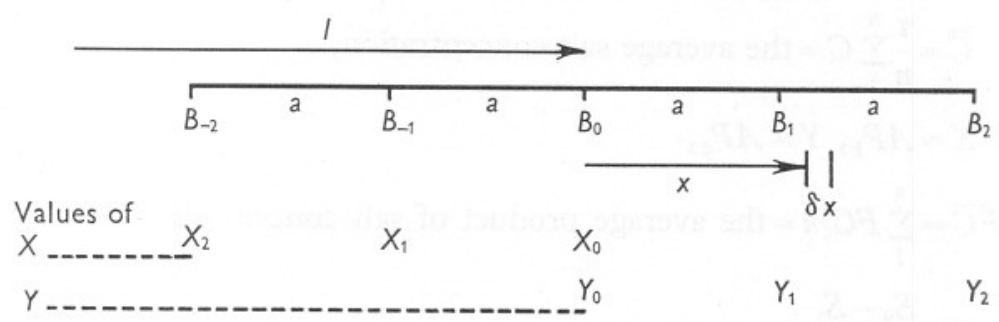

Fig. 2. Diagram of symbols used in calculation by relaxation.

Consider a point, $B_{0}$, at a distance $l$ along the estuary (Fig. 2), and let $A$ be the average area of cross-section of the river at half-tide. During a tidal cycle, salt in the water in the neighbourhood of $B_{0}$ is caused to flow past $B_{0}$ by the mixing. From a section between distances of $x$ and $x+\delta x$ from $B_{0}$, the amount of salt which is carried past $B_{0}$ by the mixing during time $T$ is

$$
\frac{L-x}{L} C A P_{2} \delta x \text {, }
$$

where $C$ is the concentration of salt in the water, and the amount of salt which flows past $B_{0}$ during $n$ intervals of time $T$ is

$$
\sum_{1}^{n} C A P_{2} \frac{L-x}{L} \delta x \text {. }
$$

The values of $C, A, P_{2}$ and $L$ are, of course, those at the point $\mathrm{I}+x$.

The net amount of salt which is carried upstream past $B_{0}$ during the $n$ intervals of time, $T$, is

$$
\int_{0}^{L} \sum_{1}^{n} C A P_{2} \frac{L-x}{L} \mathrm{~d} x+\int_{0}^{-L} \sum_{1}^{n} C A P_{1} \frac{L+x}{L} \mathrm{~d} x .
$$

The amount carried seaward by the flow of water along the estuary is $\sum_{1}^{n} F C$, where $F$ is the net flow of land water during I interval of time, $T$. From condition (i)

$$
\begin{aligned}
\frac{\mathrm{I}}{n}\left[\int_{0}^{L} \sum_{1}^{n} C A P_{2} \frac{L-x}{L} \mathrm{~d} x+\int_{0}^{-L} \sum_{1}^{n} C A P_{1} \frac{L+x}{L} \mathrm{~d} x\right] \\
=\frac{\mathrm{I}}{n}\left[\sum_{1}^{n} F C+S_{2}-S_{1}\right],
\end{aligned}
$$


where $S_{2}$ and $S_{1}$ are the amounts of salt above $B_{0}$ at the end and the beginning of the period respectively. Or

$$
\int_{0}^{L} \bar{C} Y \frac{L-x}{L} \mathrm{~d} x+\int_{0}^{-L} \bar{C} X \frac{L+x}{L} \mathrm{~d} x=\overline{F C}+S,
$$

where $\bar{C}=\frac{\mathrm{I}}{n} \sum_{1}^{n} C=$ the average salt concentration,

$$
\begin{aligned}
X & =A P_{1}, Y=A P_{2}, \\
\overline{F C} & =\sum_{1}^{n} F C / n=\text { the average product of salt concentration and flow, } \\
S & =\frac{S_{2}-S_{1}}{n} .
\end{aligned}
$$

Similarly, from condition (ii)

$$
\int_{0}^{L} Y \frac{L-x}{L} \mathrm{~d} x+\int_{0}^{-L} X \frac{L+x}{L} \mathrm{~d} x=0 .
$$

From records of the salinities and of the flows of fresh water into the estuary, the numerical values of $\bar{C}$ and $\overline{F C}$ can be computed for the places of sampling and can be obtained at intermediate points by interpolation. The period for which the means are found should be long enough to give average conditions. The individual readings are not required to obtain $X$ and $Y$, which are calculated from equations (3) and (4); only the averages $\bar{C}$ and $\overline{F C}$ are necessary. The values of $\bar{C}$ for the Thames Estuary from I January to I8 December are shown in Fig. 3. This graph, and a similar graph of $\overline{F C}$, provided the only experimental data of salinities which were used in the calculation of the values of $X$ and $Y$ for the Thames Estuary.

\section{Solution by relaxation}

Equations (3) and (4) have to be solved for $X$ and $Y$ numerically. This can be done by the relaxation method.

Let $B_{-2}, B_{-1}, B_{0}, B_{1}, B_{2}$ be points along the estuary, each separated by the distance $a$ (Fig. 2), let $X_{2}, X_{1}, X_{0}$ be the values of $X$ at $B_{-2}, B_{-1}, B_{0}$ respectively, and let $Y_{0}, Y_{1}, Y_{2}$ be the values of $Y$ at $B_{0}, B_{1}, B_{2}$, respectively.

As a first approximation, $X, Y$ and $\bar{C}$ may be considered as linear functions of distance within the range of the mixing length $L$ and

$$
\begin{aligned}
& X=X_{0}-\left(X_{1}-X_{0}\right) x / a \text { from } B_{0} \text { to } B_{-1}, \\
& Y=Y_{0}+\left(Y_{1}-Y_{0}\right) x / a \text { from } B_{0} \text { to } B_{1}, \\
& \bar{C}=C_{0}+C_{1} x \text { from } B_{-1} \text { to } B_{1},
\end{aligned}
$$

where $C_{0}$ and $C_{1}$ are constants, and $x$ is the distance from $B_{0}$. 
Substitution in equations (3) and (4), and simplification, gives

$$
2 X_{0} L^{2}+2 Y_{0} L^{2}+\frac{\left(Y_{1}-Y_{0}\right) L^{3}}{a}+\frac{\left(X_{1}-X_{0}\right) L^{3}}{a}=\frac{\mathrm{I} 2 Q}{C_{1}},
$$

and

$$
3 Y_{0} L-3 X_{0} L+\frac{\left(Y_{1}-Y_{0}\right) L^{2}}{a}-\frac{\left(X_{1}-X_{0}\right) L^{2}}{a}=0,
$$

where $Q=\overline{F C}+S$.

Equations (5) and (6) exist for all the points in the estuary, and can be used to obtain the approximate values of $X$ and $Y$ at a series of points by the relaxation method. If $a=L$, equations (5) and (6) become

$$
\begin{gathered}
X_{0}+Y_{0}+Y_{1}+X_{1}=\mathrm{I} 2 Q / L^{2} C_{1}, \\
2 Y_{0}-2 X_{0}+Y_{1}-X_{1}=0 .
\end{gathered}
$$

To obtain greater accuracy it is necessary to take $\bar{C}, X$ and $Y$ as quadratic functions of distance in the range of the mixing lengths and put

$$
\begin{gathered}
X=X_{0}-\frac{\left(4 X_{1}-3 X_{0}-X_{2}\right) x}{2 a}+\frac{\left(X_{2}+X_{0}-2 X_{1}\right) x^{2}}{2 a^{2}}, \\
Y=Y_{0}+\frac{\left(4 Y_{1}-3 Y_{0}-Y_{2}\right) x}{2 a}+\frac{\left(Y_{2}+Y_{0}-2 Y_{1}\right) x^{2}}{2 a^{2}}, \\
\bar{C}=C_{0}+C_{1} x+C_{2} x^{2},
\end{gathered}
$$

where $C_{0}, C_{1}$ and $C_{2}$ are constants. On substitution, equations (3) and (4) become

$$
\begin{aligned}
& X_{0}\left[10 C_{1} L^{2}-{ }_{5} C_{2} L^{3}\right]+Y_{0}\left[10 C_{1} L^{2}+{ }_{5} C_{2} L^{3}\right]+\left[4 Y_{1}-3 Y_{0}-Y_{2}\right]\left[{ }_{5} C_{1} L^{3}\right. \\
& \left.+{ }_{3} C_{2} L^{4}\right] / 2 a+\left[4 X_{1}-3 X_{0}-X_{2}\right]\left[5 C_{1} L^{3}-{ }_{3} C_{2} L^{4}\right] / 2 a+\left[X_{2}+X_{0}-2 X_{1}\right] \\
& \times\left[{ }_{3} C_{1} L^{4}-2 C_{2} L^{5}\right] / 2 a^{2}+\left[Y_{2}+Y_{0}-2 Y_{1}\right]\left[{ }_{3} C_{1} L^{4}+2 C_{2} L^{5}\right] / 2 a^{2}=60 Q, \\
& 6 X_{0} L-6 Y_{0} L+\left(4 X_{1}-3 X_{0}-X_{2}\right) L^{2} / a-\left(4 Y_{1}-3 Y_{0}-Y_{2}\right) L^{2} / a \\
& +\left(X_{2}+X_{0}-2 X_{1}\right) L^{3} / 2 a^{2}-\left(Y_{2}+Y_{0}-2 Y_{1}\right) L^{3} / 2 a^{2}=0 .
\end{aligned}
$$

If $2 a=L$, equations ( 9 ) and (10) become

$$
C_{1}\left[X_{0}+Y_{0}+8 X_{1}+8 Y_{1}+X_{2}+Y_{2}\right]+L C_{2}\left[4 Y_{1}-4 X_{1}+Y_{2}-X_{2}\right]=60 Q / L^{2}
$$

and

$$
2 X_{1}-2 Y_{1}+X_{0}-Y_{0}=\text { o. }
$$

These equations can be used to improve the values obtained from the linear equations. It is advisable to obtain the first approximate solution for a set of points whose distances apart are $L$ and then to introduce the values of $X$ and $Y$ at points midway between the first points when the quadratic equations are used. Group relaxation greatly shortens the work. Decreasing the distance between the points does not produce greater accuracy, unless the values at all the points within the range of the integral are used to give more accurate 
relaxation formulae. If $3 a<L$, cubic or higher equations have to be used, and the relaxation becomes very cumbersome and difficult. If greater accuracy than that obtainable by the quadratic equations is required, it is better to use numerical integration or some other method. A little experience will show how to diminish the remaining error when this is found by numerical integration.

Any values of $X$ and $Y$ may be assumed at the start of the relaxation, but time will be saved if these values are reasonably accurate. For the period selected for the Thames Estuary it was found that for a long distance both $\bar{C}$ and $Q$ were approximately linear functions of distance given by

$$
\begin{aligned}
& \bar{C}=\theta_{1}(l+2), \\
& Q=\theta_{2}(l+2),
\end{aligned}
$$

where $\theta_{1}$ and $\theta_{2}$ are constants, and $l$ is the distance in miles from London Bridge. Substitution in equations (3) and (4) shows that the following equations are good approximate solutions:

$$
\begin{aligned}
& X=\frac{3 l+6+L}{L^{2}} \frac{\theta_{2}}{\theta_{1}}, \\
& Y=\frac{3 l+6-L}{L^{2}} \frac{\theta_{2}}{\theta_{1}} .
\end{aligned}
$$

The values given by equations (I5) and (I6) were used as the initial values in the relaxation for the Thames Estuary.

\section{Salinity \\ SOURCES OF INFORMATION FOR THE THAMES EstUARY}

The London County Council has a very extensive record of the salinities of the Thames Estuary from London Bridge to the Nore, from I920 to the present day. Salinities of samples taken at a depth of $6 \mathrm{ft}$. in mid-stream are recorded weekly at many sampling positions. Times of sampling vary, but most of the samples from any one position have been taken at about the same state of the tide. The London County Council very kindly allowed full use to be made of these records.

\section{Tides}

The Port of London Authority has supplied much information regarding the tides, including the results of simultaneous tidal surveys at many points in the estuary. Data from the Admiralty Tide Tables have also been used.

\section{Flow}

The Thames Conservancy records the daily flow over Teddington Weir. Low flows are measured with accuracy, but there may be greater error in the high winter flows. Figures for the flow of tributaries and effluents have been 
provided by River Boards, Local Authorities, and industries. Much information has also been obtained from the survey of the estuary now being made.

\section{Correction of salinity position}

The readings of the L.C.C. cannot be used directly to find the salinity gradient along the estuary, as samples from different points are taken at different states of the tide. The fact that there is little salinity variation in a cross-section of the estuary, suggests that when the salinities of the estuary

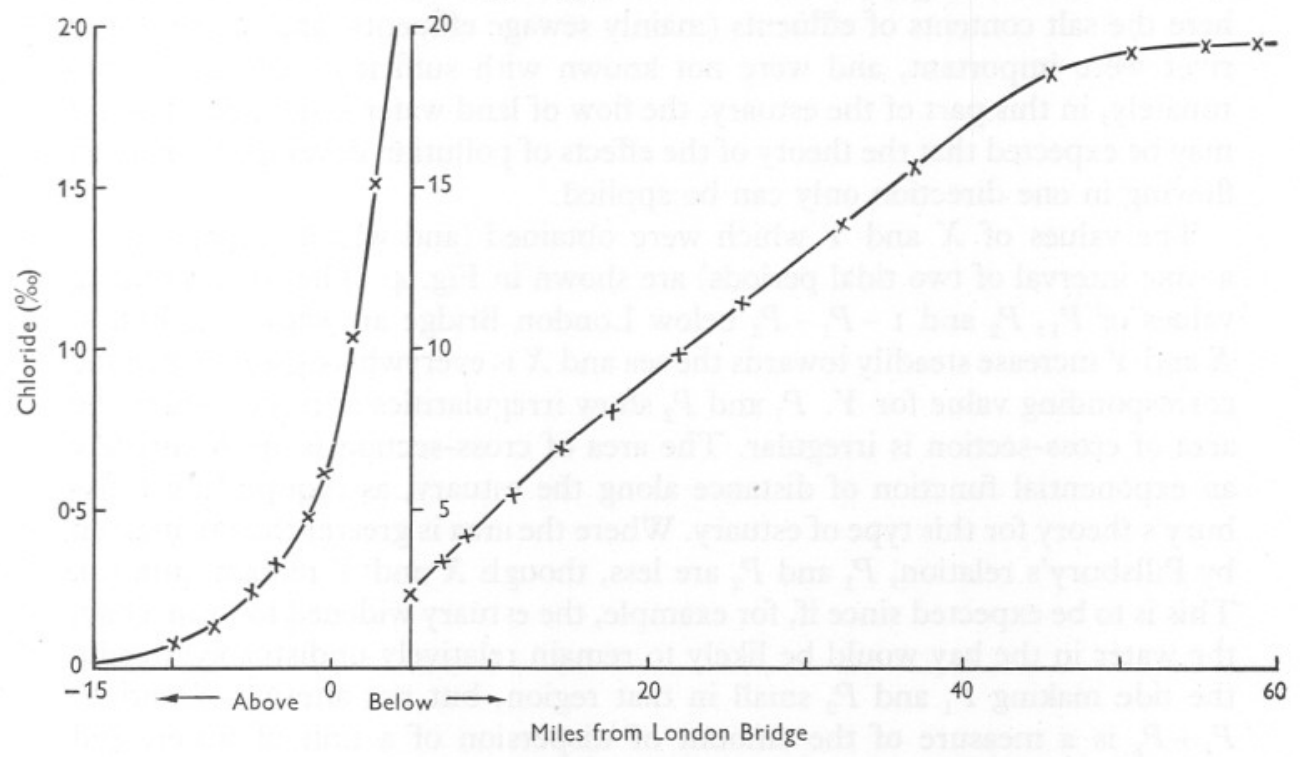

Fig. 3. Average contents of chloride in the Thames Estuary, I January to I8 December 1948. Chloride given as parts per thousand.

are in equilibrium, water of a constant salinity moves with the tide so that the volume of water between it and Teddington Weir is constant. If this is so, then the position of a sample can be adjusted to a half-tide position so that the volume of water between the sample and Teddington Weir remains the same. This has been done for a great number of observations and it has been found that salinities and concentrations of chemicals dissolved in the water then fall on a smooth curve. The correction may be large compared with the distance between the sampling points. Fig. 3 shows a corrected curve for the average values of the salinities from I January to I8 December I 948 plotted against distance along the estuary.

\section{RESUlTS FOR THE THAMES ESTUARY}

In calculating the extent of mixing in the Thames estuary, $L$ was given the value 4.5 miles for mixing during half of the average tidal period, i.e. for $T=6 \mathrm{~h} \mathrm{I} 2 \frac{1}{2} \mathrm{~min}$. For $T=24 \mathrm{~h} 50 \mathrm{~min}$, the time of two tides, $L$ was given the 
value of 9 miles. The calculation was made from the average values of salt concentration, and the average values of the product of salt concentration and volume of land water entering the landward section of the estuary, from I January to I8 December 1948. A longer period could not be used because of lack of information regarding the flows of the tributaries of the estuary at other times. Above London Bridge the average value of salt concentration became small, and in the section of the estuary near to Teddington (I9 miles above London Bridge) $X$ and $Y$ could not be obtained accurately because here the salt contents of effluents (mainly sewage effluents) and of the upper river were important, and were not known with sufficient accuracy. Fortunately, in this part of the estuary, the flow of land water is dominant, and it may be expected that the theory of the effects of pollution developed for rivers flowing in one direction only can be applied.

The values of $X$ and $Y$ which were obtained (and which correspond to a time interval of two tidal periods) are shown in Fig. 4. The corresponding values of $P_{1}, P_{2}$ and $\mathrm{I}-P_{1}-P_{2}$ below London Bridge are shown in Fig. 5. $X$ and $Y$ increase steadily towards the sea and $X$ is everywhere greater than the corresponding value for $Y . P_{1}$ and $P_{2}$ show irregularities at places where the area of cross-section is irregular. The area of cross-section is approximately an exponential function of distance along the estuary, as required by Pillsbury's theory for this type of estuary. Where the area is greater than that given by Pillsbury's relation, $P_{1}$ and $P_{2}$ are less, though $X$ and $Y$ remain uniform. This is to be expected since if, for example, the estuary widened to form a bay, the water in the bay would be likely to remain relatively undisturbed during the tide making $P_{1}$ and $P_{2}$ small in that region, but not altering $X$ and $Y$. $P_{1}+P_{2}$ is a measure of the amount of dispersion of a unit of water, and this varies along the estuary, being a maximum 25 miles below London Bridge.

$X, Y, P_{1}$ and $P_{2}$ probably vary with different ranges of tide. The values obtained are averages for the tides of the period considered.

\section{Verification}

If the salinities at a given time and the flows of fresh water during the following period are known, the salinity at the end of the period may be predicted from a knowledge of $X$ and $Y$ obtained from equations (3) and (4). The period must be divided into intervals of time for which the mixing values have been found, and the salinity at the end of each successive interval can be found by: (I) displacing the water to allow for the natural flow, and then (2) calculating the new salinities at a number of points by numerical integration of the expression

$$
\frac{\mathrm{I}}{A}\left[\int_{0}^{L} \frac{C Y}{L} \mathrm{~d} x+\int_{-L}^{0} \frac{C X}{L} \mathrm{~d} x+C(A-X-Y)\right],
$$




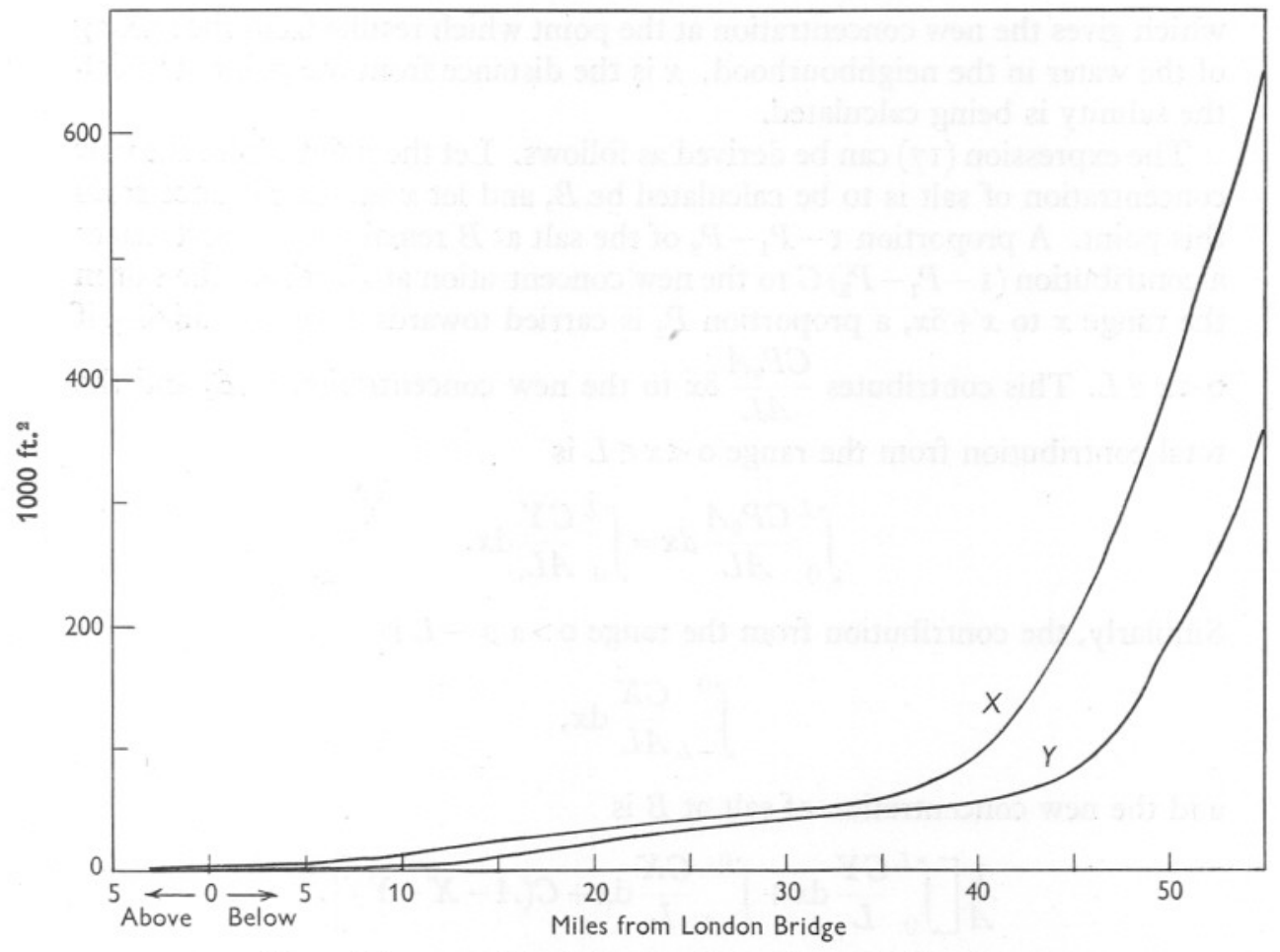

Fig. 4. Values for $X$ and $Y$ when $T$ equals two tidal periods.

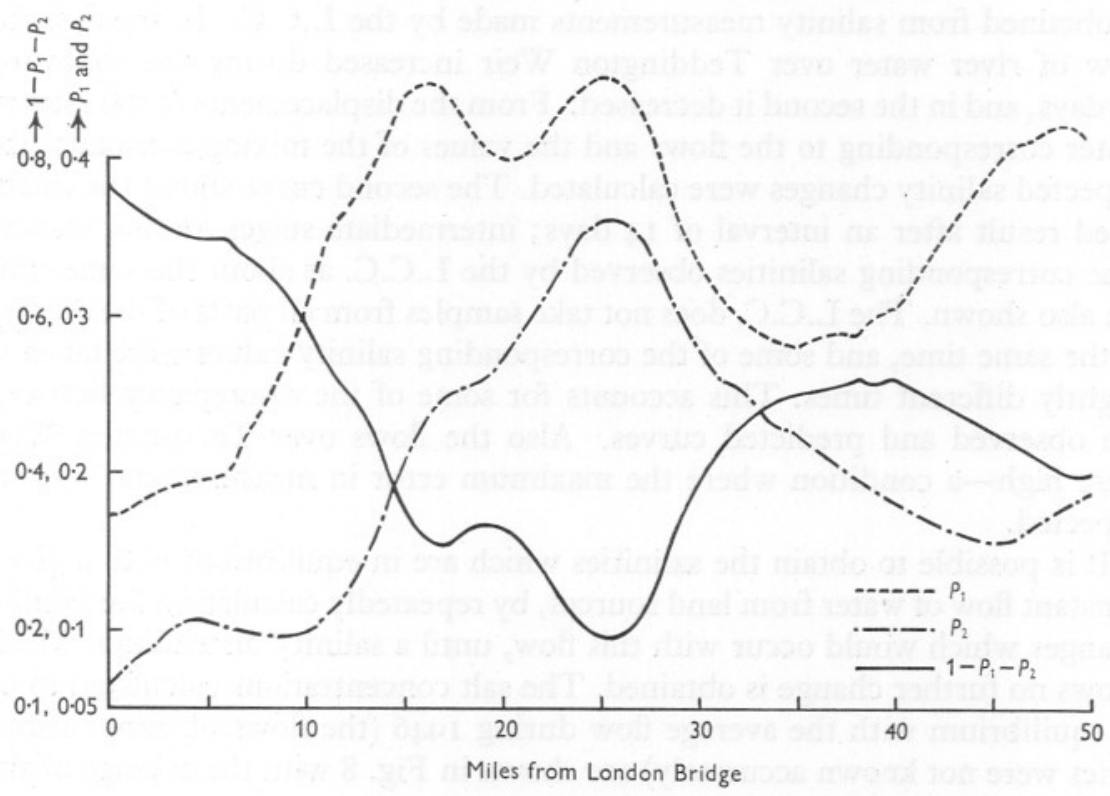

Fig. 5. Values of $P_{1}$ and $P_{2}$ for a period of two tides. 
which gives the new concentration at the point which results from the mixing of the water in the neighbourhood. $x$ is the distance from the point at which the salinity is being calculated.

The expression ( $\mathrm{I} 7$ ) can be derived as follows. Let the point where the new concentration of salt is to be calculated be $B$, and let $x$ be the distance from this point. A proportion $\mathrm{I}-P_{1}-P_{2}$ of the salt at $B$ remains there and makes a contribution $\left(\mathrm{I}-P_{1}-P_{2}\right) C$ to the new concentration at $B$. From the salt in the range $x$ to $x+\delta x$, a proportion $P_{2}$ is carried towards $B$ by the mixing if $0<x<L$. This contributes $\frac{C P_{2} A}{A L} \delta x$ to the new concentration at $B$, and the total contribution from the range $0<x<L$ is

$$
\int_{0}^{L} \frac{C P_{2} A}{A L} d x=\int_{0}^{L} \frac{C Y}{A L} \mathrm{~d} x
$$

Similarly, the contribution from the range $0>x>-L$ is

$$
\int_{-L}^{0} \frac{C X}{A L} \mathrm{~d} x
$$

and the new concentration of salt at $B$ is

$$
\frac{\mathrm{I}}{A}\left[\int_{0}^{L} \frac{C Y}{L} \mathrm{~d} x+\int_{-L}^{0} \frac{C X}{L} \mathrm{~d} x+C(A-X-Y)\right] .
$$

Figs. 6 and 7 show the results of two calculations. Curve $\mathrm{I}$ of both figures is obtained from salinity measurements made by the L.C.C. In the first the flow of river water over Teddington Weir increased during the following I4 days, and in the second it decreased. From the displacements of the estuary water corresponding to the flows and the values of the mixing constants, the expected salinity changes were calculated. The second curve shows the calculated result after an interval of 14 days; intermediate stages are not shown. The corresponding salinities observed by the L.C.C. at about the same time are also shown. The L.C.C. does not take samples from all parts of the estuary at the same time, and some of the corresponding salinity values were taken at slightly different times. This accounts for some of the discrepancy between the observed and predicted curves. Also the flows over Teddington Weir were high-a condition where the maximum error in measurement is to be expected.

It is possible to obtain the salinities which are in equilibrium with a given constant flow of water from land sources, by repeatedly calculating the salinity changes which would occur with this flow, until a salinity distribution which shows no further change is obtained. The salt concentrations calculated to be in equilibrium with the average flow during 1946 (the flows of minor tributaries were not known accurately) are shown in Fig. 8 with the average of the 


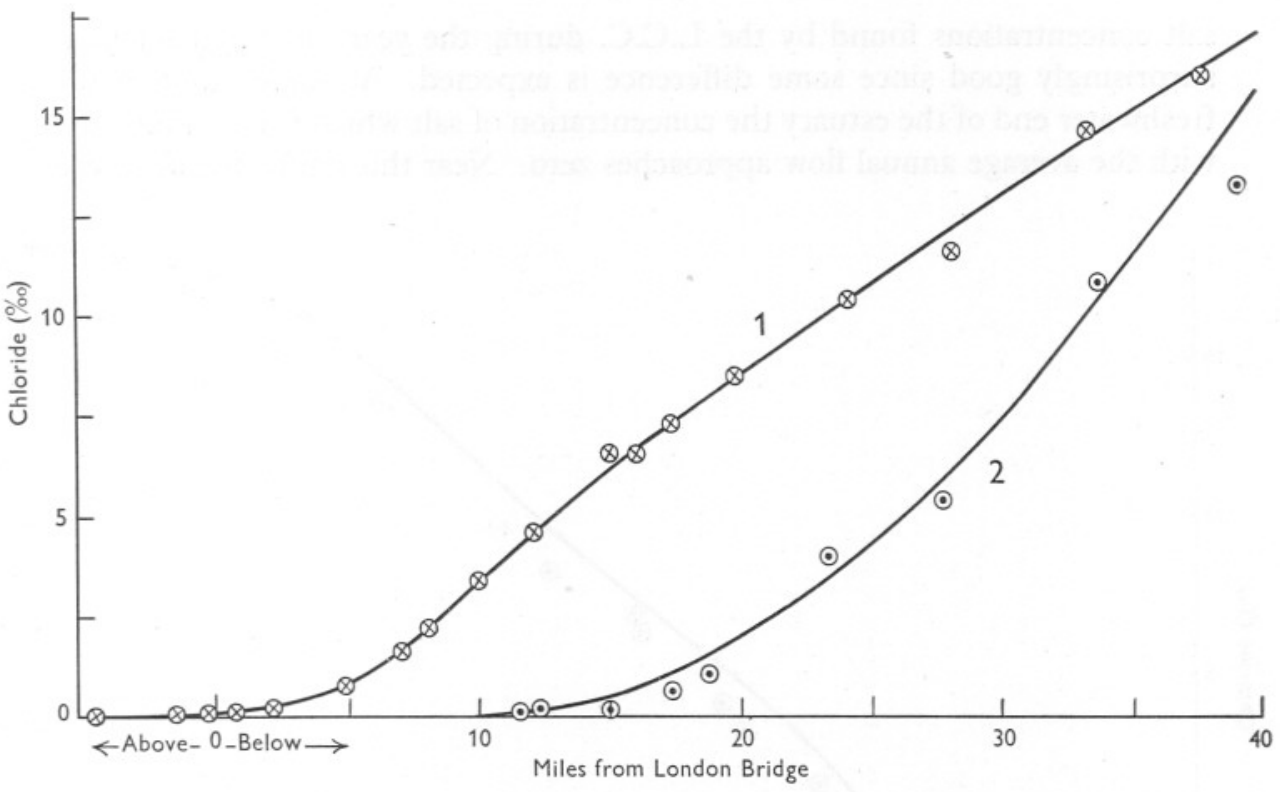

Fig. 6.

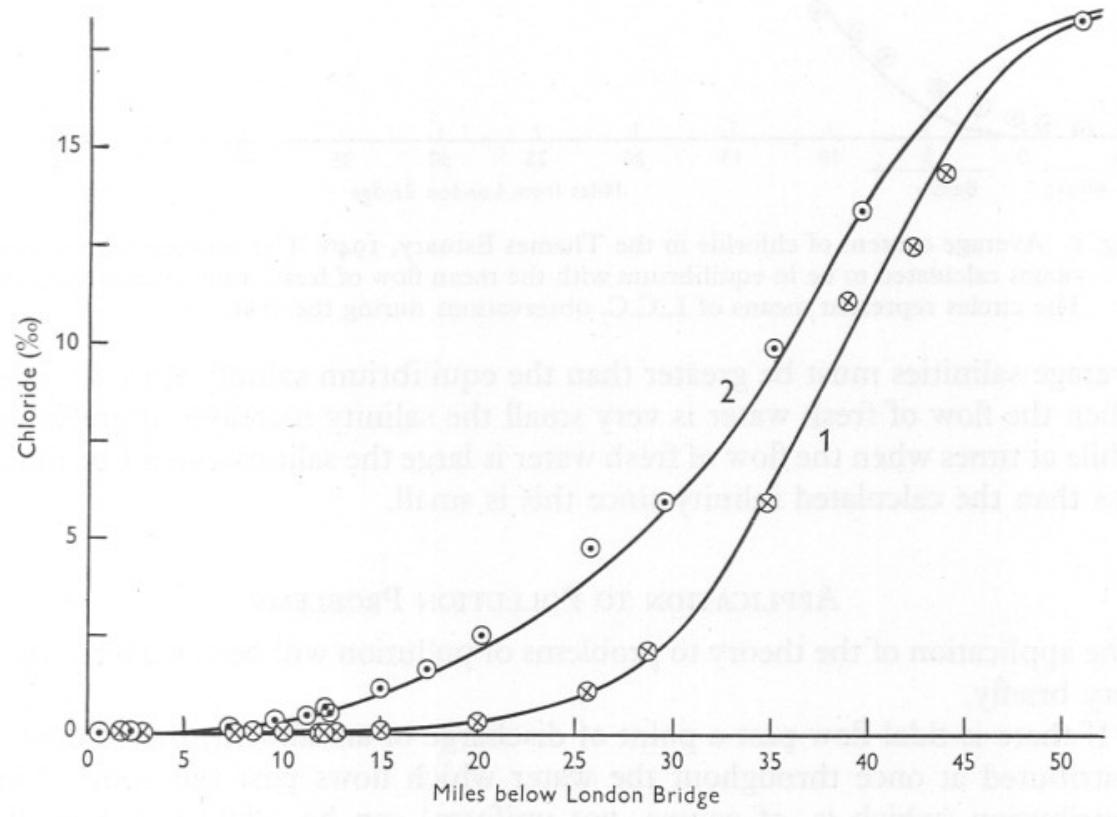

Fig. 7 .

Figs. 6 and 7. Curves showing accuracy of calculation of changes in salinity in the Thames Estuary. Curve I was plotted through the readings $\otimes$ taken on a zero date. Curve 2 was calculated from curve I, being an estimate for the conditions I4 days later. The readings $\odot$ were the observed values on that day. 
salt concentrations found by the L.C.C. during the year. The agreement is surprisingly good since some difference is expected. At some point in the freshwater end of the estuary the concentration of salt which is in equilibrium with the average annual flow approaches zero. Near this point, the observed

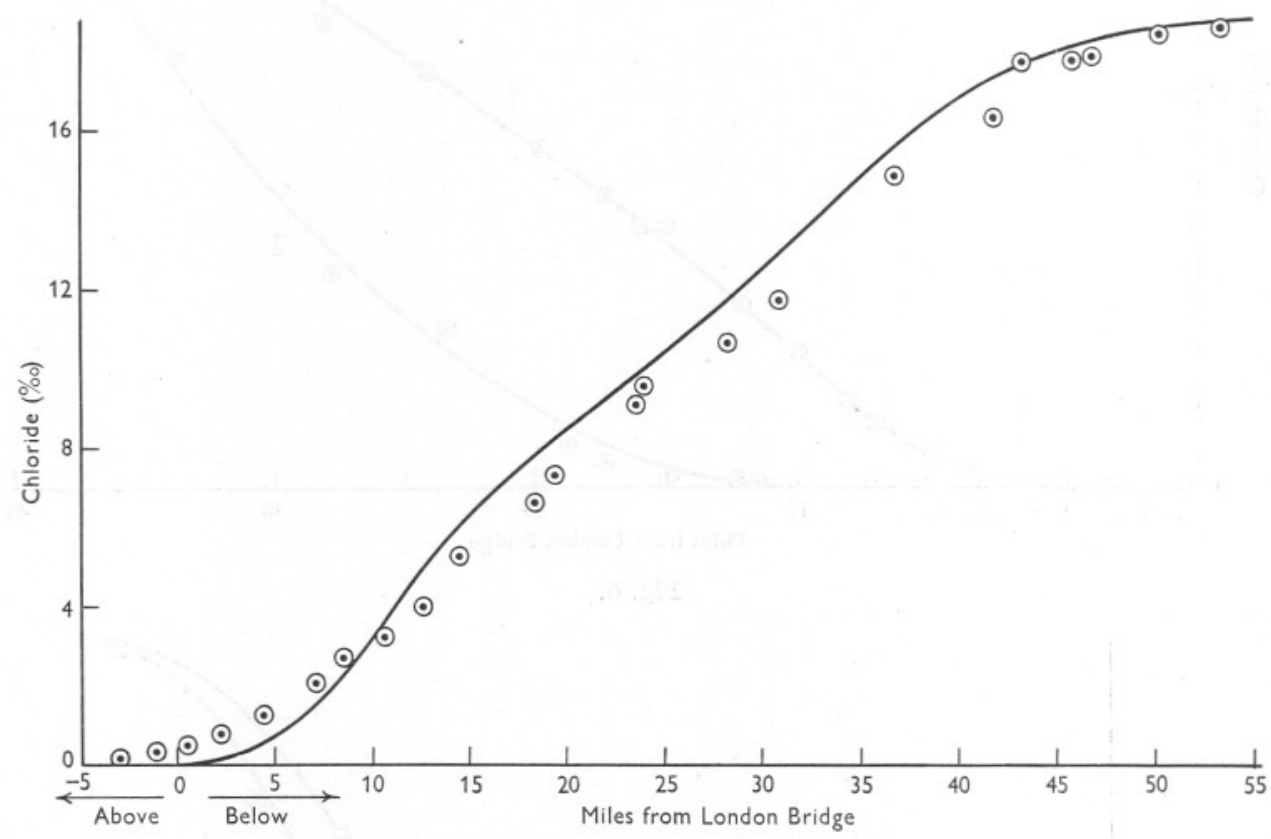

Fig. 8. Average content of chloride in the Thames Estuary, 1946. The continuous line plots values calculated to be in equilibrium with the mean flow of fresh water during the year. The circles represent means of L.C.C. observations during the year.

average salinities must be greater than the equilibrium salinity since at times when the flow of fresh water is very small the salinity increases appreciably, while at times when the flow of fresh water is large the salinity cannot be much less than the calculated salinity since this is small.

\section{Application to Pollution Problems}

The application of the theory to problems of pollution will be considered only very briefly.

If there is tidal flow past a point of discharge of an effluent, the effluent is distributed at once throughout the water which flows past the point. This distribution (which is, of course, not uniform) can be calculated from the tidal data and is equivalent to a discharge over a length $2 L$ at half-tide. Hence the initial concentration of the effluent in the water can be found and the concentration at any point at a later time can be calculated by the process already 
given for salinities. Fig. 9 shows the calculated distributions along the Thames Estuary of the effluent discharged from the Northern Outfall of the L.C.C. when the flow of fresh water over Teddington Weir is 500 million gallons per day. The extent of pollution of the water, as measured by the biochemical oxygen demand, can be calculated from these curves if the rate at which the

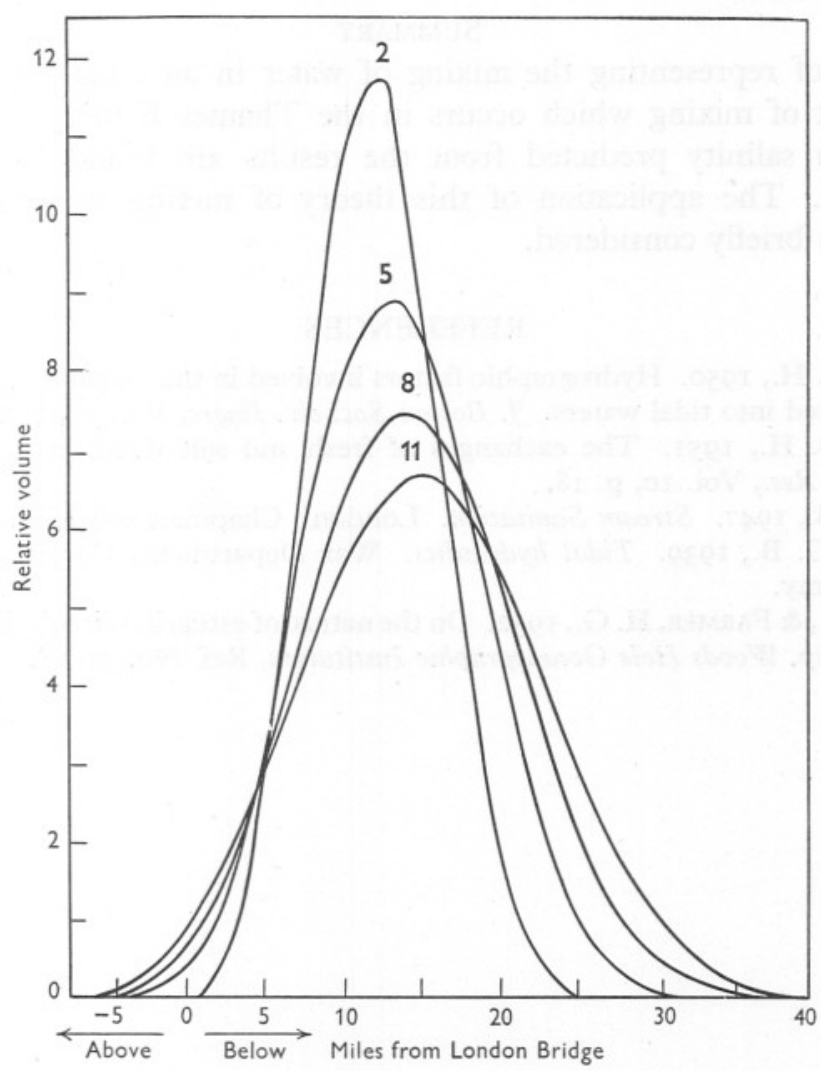

Fig. 9. Computed distribution of a liquid discharged into the Thames Estuary, during a period between low and high water, at the Northern Outfall of the London County Council sewage-disposal works. The number of tidal cycles after discharge is shown against each curve. The vertical scale shows the comparative volume of added liquids per unit length of river. Flow of fresh water at Teddington $=500 \mathrm{~m}$.g.d.

demand is satisfied is known. If the rate of solution of oxygen from the air is also known, it is then possible to calculate the level of oxygenation of the water, using the mixing constants. For the Thames Estuary, where there are a great number of discharges, the calculation by this method is very tedious, but it seems likely that methods can be developed which will simplify the arithmetical work involved. 
Much of the numerical calculation for this work was done by Mr L. J. Jeeves, who also collected many of the data, and made many useful suggestions. I should like to thank Mr C. J. Regan, Chief Chemist of the L.C.C., for many valuable discussions.

This paper is published by permission of the Department of Scientific and Industrial Research.

\section{SUMMARY}

A method of representing the mixing of water in an estuary is given, and the amount of mixing which occurs in the Thames Estuary is calculated. Changes in salinity predicted from the results are found to agree with observation. The application of this theory of mixing to some pollution problems is briefly considered.

\section{REFERENCES}

Ketchum, B. H., I950. Hydrographic factors involved in the dispersion of pollutants introduced into tidal waters. F. Boston Soc. civ. Engrs, Vol. 37, No. 3, p. 296.

Ketchum, B. H., I95I. The exchanges of fresh and salt water in tidal estuaries. f. Mar. Res., Vol. Io, p. I8.

Phelps, E. B., I947. Stream Sanitation. London. Chapman and Hall.

Pillsbury, G. B., I939. Tidal hydraulics. War Department, Corps of Engineers, U.S. Army.

StomMel, H., \& FARMER, H. G., I952. On the nature of estuarine circulation. Part III. Tech. Rep. Woods Hole Oceanographic Institution, Ref. No. 52-88. 